\title{
Árboles del Valle Central de Costa Rica: reproducción
}

\section{Aromo}

Freddy Rojas-Rodríguez ${ }^{1}$ Gustavo Torres-Córdoba²

\section{Resumen}

Se presenta una breve descripción del árbol de aromo Acacia farnesiana (L.) Willd., e información sobre fenología como base para la recolección de frutos, el manejo de las semillas, la viverización y el proceso de germinación.

Palabras clave: Acacia farnesiana, fenología, manejo de semillas, viverización, germinación, árboles, Costa Rica.

\section{Abstract}

Trees of the Central Valley of Costa Rica: reproduction. Aromo. The following issue presents a brief description about the "aromo" tree (Acacia farnesiana (L.) Willd.) including information about its phenology which directly relates to fruit recollection, seed treatment, nursery, and germination processes.

Key words: Acacia farnesiana, phenology, seeds treatments, management at nursery, germination, trees, Costa Rica.

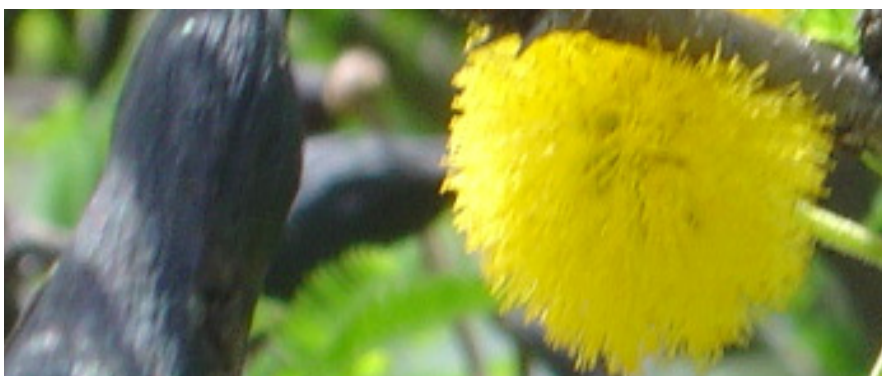

Figura 1. Flor del aromo.

1. Escuela de Ing. Forestal - Instituto Tecnológico de Costa Rica. freddyrojasrodriguez@gmail.com

2. Escuela de Ing. Forestal - Instituto Tecnológico de Costa Rica. gtorres@tec.ac.cr Tel: (506) 2550- 2039

\section{Taxonomía}

Nombre científico: Acacia farnesiana (L.) Willd.

Nombre común: Aromo, espino blanco y acacia dulce.

Familia: Fabaceae - Mimosaceae

Origen: Nativa

\section{Distribución en el mundo}

Desde Estados Unidos hasta Argentina (principalmente en el pacífico seco) (Barwick 2004). Sin embargo; Hoyos (1994) indica que la especie también se encuentra en regiones similares en Australia y África del Sur.

\section{Distribución en Costa Rica}

Principalmente en el Pacífico Seco, ocasionalmente se encuentra como ornamental en el Valle Central.

\section{Descripción}

Árbol mediano tipo arbusto, antes de copa uniforme y compacta, las hojas se desarrollan a lo largo del ramaje. Su fuste es espinoso, de mala forma, muy ramificado desde la base. (Chavarría et al. 2000) La corteza está compuesta por delgadas espinas blancas grisáceas, de 5 a $6 \mathrm{~mm}$ de espesor; lisa cuando joven y fisurada en su edad adulta.

Presenta un follaje semicaducifolio, sus hojas son compuestas y bipinnadas, alternas. De 2 a 6 pares de pinnas y de 10 a 20 pares foliolos. Posee foliolos de $5 \mathrm{~mm}$ de largo y su pecíolo presenta una pequeña glándula cerca del primer par de pinnas (León y Poveda 2000).

Muchas flores diminutas conforman sus inflorescencias esféricas, amarillas, compactas y muy fragantes, de 1 a $2 \mathrm{~cm}$ de diámetro. La especie se cultiva mucho en Francia por el uso de las flores en perfumería, en Costa Rica se utilizan como aromatizante. 
Sus frutos son en forma de vaina ligeramente curveada, gruesa, de 4 a $8 \mathrm{~cm}$ de largo, color castaño o negruzco y permanece adherido a la rama después de la madurez.

Contiene una pulpa dulce. Tanto el fruto como la cáscara de este se usan para curtir cueros.

Las semillas son pequeñas, elípticas, brillantes, color café con testa dura. El ganado come la pulpa que rodea la semilla.

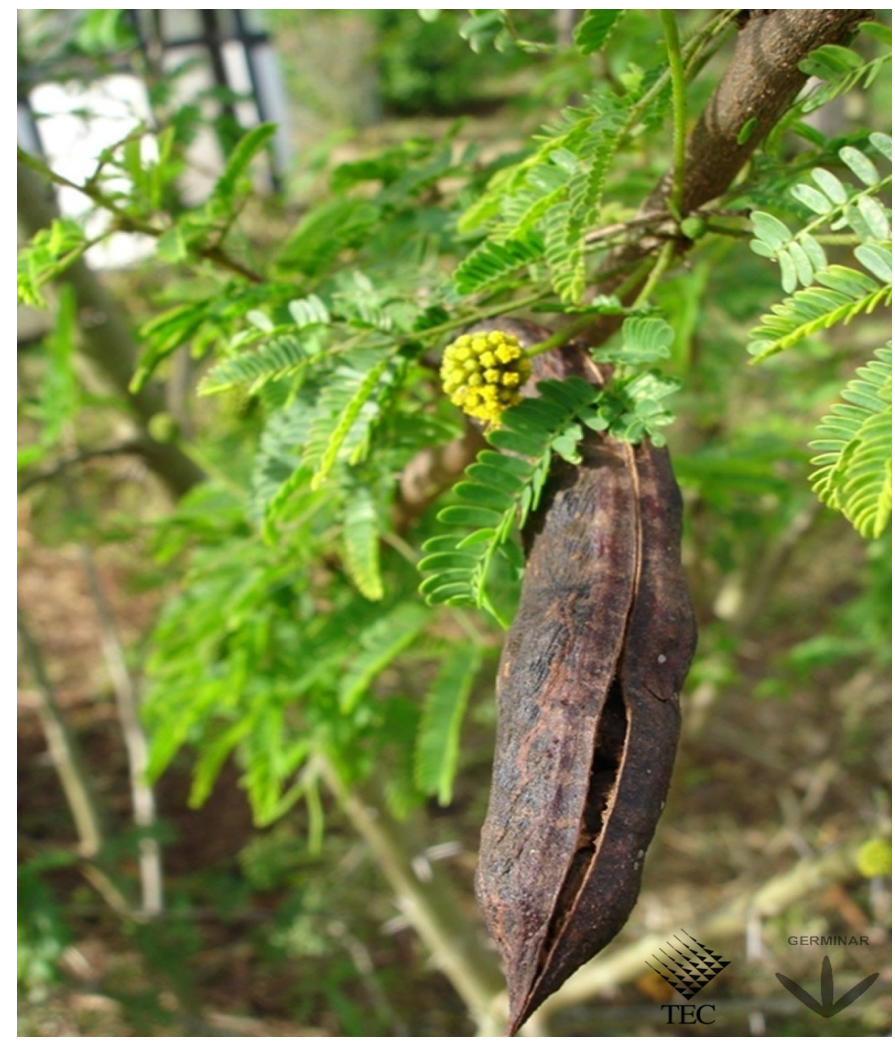

Figura 2. Flores y fruto del aromo.

\section{Dendrofenocronograma}

Se presenta a continuación información fenológica del aromo, para la región central de Costa Rica.

Tabla 1. Dendrofenocronograma del aromo en la región central de Costa Rica.

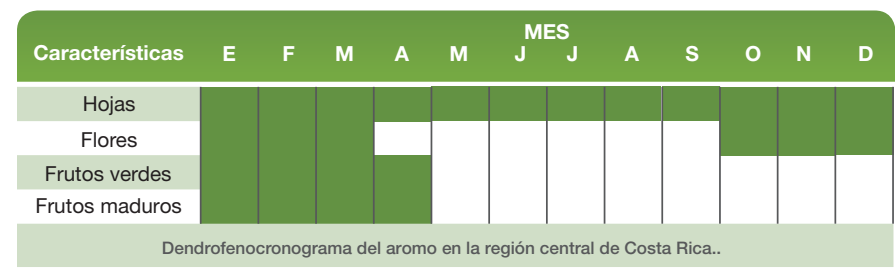

\section{Manejo de semilla y viverización}

Los frutos maduros del aromo se recolectan de enero a abril. Su madurez se reconoce por su color.

Para logar la germinación, las semillas se siembran en forma de puntos o surcos, en un sustrato compuesto a base de tierra más arena. Esta se debe cubrir apenas sub superficialmente. La germinación se experimenta 32 días después de la siembra. Su porcentaje de germinación, dependiendo de la calidad de la semilla, varía entre un 85 y un $100 \%$.

Las plántulas se encuentran listas para su repique o trasplante una semana posterior a la germinación. Se puede usar una variedad de sistemas de producción para lograr plántulas bien desarrolladas, a saber: bolsa plástica, contenedores, raíz desnuda, paper pot, pseudoestaca, estaca y jiffy. En cuanto al mantenimiento, es indispensable aplicar sombra, así como fertilización química u orgánica (Torres et al. 2011).

\section{Proceso de Germinación}

El tipo de germinación del aromo es epigea, según la siguiente ilustración.

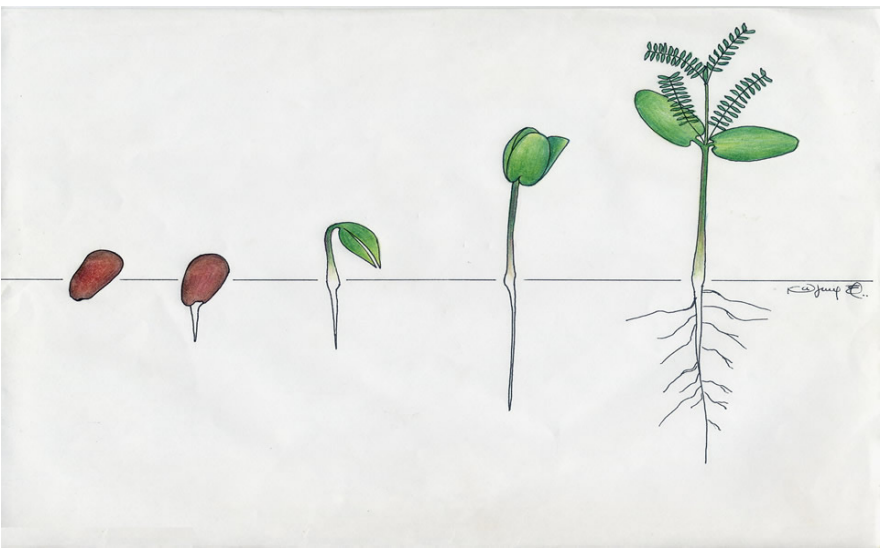

Figura 3. Proceso de germinación del aromo.

\section{Referencias}

Barwick, M. 2004. Tropical and subtropical trees. London, UK, Thames and Hudson. 484 p.

Chavarría, U; González, J; Zamora, N. 2001. Árboles comunes del Parque Nacional Palo Verde. Heredia, CR. Instituto Nacional de Biodiversidad. $216 \mathrm{p}$.

Hoyos, J. 1994. Frutales en Venezuela. Caracas, VE, Sociedad de Ciencias Naturales La Salle. 381 p.

León, J; Poveda, L. 2000. Nombres comunes de las plantas de Costa Rica. San José, CR, Editorial Guayacán. 915 p.

Torres, C; Carvajal, D; Rojas, F; Arguedas, M. 2011. Reproducción de especies arbóreas y arbustivas de la región central de Costa Rica. Germinar. Instituto Tecnológico de Costa Rica. Cartago, CR. Disponible en: http://www.tec.ac.cr/sitios/Docencia/ forestal/ Germinar/germinar\%202.html 